\title{
Doubly Triggered Rounding Harmony in Laal as Subphonemic Agreement by Correspondence*
}

\author{
Florian Lionnet \\ University of California, Berkeley
}

\section{Introduction}

In this paper, I present the doubly triggered rounding harmony of Laal, an isolate language spoken by ca. 750 people in two villages in southern Chad. This alternation is a rare and intriguing case of "phonological teamwork," i.e. a process involving more than one trigger (Lionnet in prep.), involving subphonemic cumulative effects. This process is similar to the better known case of Cantonese intercoronal fronting (Flemming 1997, 2001), a morpheme structure constraint preventing a back rounded vowel from surfacing between two coronal consonants, illustrated in (1) below:

(1) $* \mathrm{TuT}>\mathrm{TyT}$

$\begin{array}{lllll}\text { a. } & \mathrm{k}^{\text {hyt }} & \text { 'decide' } & \mathrm{k}^{\mathrm{h}} \mathrm{ut} & \text { 'bracket' } \\ \text { b. } & \mathrm{t}^{\mathrm{h}} \mathrm{uk} & \text { 'bald head' } & & \\ \text { c. } & \mathrm{t}^{\mathrm{h}} \mathrm{yt} & \text { 'take off' } & * \mathrm{t}^{\mathrm{h}} \mathrm{ut} & \end{array}$

Note that one adjacent coronal consonant is allowed, but not two: the fronting effect of a coronal consonant is not strong enough to trigger vowel fronting, two triggers are needed.

Based on this and similar alternations Flemming claims that "cases of doubly-conditioned assimilation (...) provide evidence that coarticulation is relevant to uncontroversially phonological processes, and therefore must be represented in the phonology." I fully agree with this statement, and argue in the present paper for an enrichment of Agreement by Correspondence theory.

I will first present the Laal doubly triggered rounding harmony of Laal (section 2) and the subphonemic similarity threshold effects at work (section 3). I will then argue in favor of a phonological status of said effects (section 4) and propose an analysis based on a modified version of Agreement by Correspondence showing that $\mathrm{ABC}$ can advantageously handle local effects of assimilation as well as longdistance assimilation (section 5). I then conclude in section 6.

\section{Laal doubly triggered rounding harmony}

Laal is a maximally disyllabic language (maximally CVC.CVC, with a few morphologically complex exceptions), with twelve phonemic vowels, presented in (2) below. Additionally, the stem initial CV sequence is prominent in Laal, which can be seen in particular in distributional asymmetries: only a subset of consonants and vowels are allowed outside of this position, which can be seen in the vowel chart in (2). ${ }^{1}$

\footnotetext{
* For helpful discussion and comments I would like to thank Larry Hyman, Sharon Inkelas, Stephanie Shih, Donca Steriade, John Sylak-Glassman as well as audiences at UC Berkeley and Stanford University. Many thanks are also due to my Laal consultants and the Laal-speaking community in Chad. This work was done as part of the "Documentation of Laal (Chad)" project funded by the DoBeS program of the Volkswagen Foundation. Any errors and infelicities are of course my own.

${ }^{1}$ Note that some vowels are diphthongized. This diphthongization shall not concern us here: diphthongized vowels behave exactly like monophthongs.
}

(C) 2014 Florian Lionnet

Supplemental Proceedings of Phonology 2013

Completed February 18, 2014 
(2)

\begin{tabular}{|c|c|c|c|c|}
\hline & \multicolumn{2}{|l|}{ V1 } & \multicolumn{2}{|c|}{ V2 } \\
\hline & + front & -front & + front & -front \\
\hline & $\mathrm{i} \quad \ddot{\mathrm{u}}[\mathrm{y}]$ & $\dot{\mathrm{i}} \mathrm{u}$ & & $\dot{\mathrm{t}} \mathrm{u}$ \\
\hline & e üo & $\partial \quad 0$ & $\mathrm{e}$ & $\partial$ \\
\hline & ia üa & a ua & -- & $\mathrm{a}$ \\
\hline
\end{tabular}

In a disyllabic word $\mathrm{CV}_{1}(\mathrm{C}) \cdot \mathrm{CV}_{2}(\mathrm{C}), \mathrm{V}_{1}$ is rounded in the presence of a round $\mathrm{V}_{2}$ only if both vowels are of identical height and backness, AND if the root contains a labial consonant /p, b, b, mb, m, w/, in any position: ${ }^{2}$ before (3a) or after (3b-c) the target vowel, as illustrated in (3) and in Figure 1 below. Given the inventory in (2), the only two triggers are /o/ and /u/, and the only two targets / / / and / $\mathbf{1} /$. The impossibility for a non-round V1 to surface in this context is both a static morpheme structucture constraint, and a active morpho-phonological process, applying in particular between a noun root and plural suffixes containing the vowel /o/ or $/ \mathrm{u} /$.

(3) V2[rd], Lab, Height, -Front, > rounding ${ }^{3}$
a. /bìr+-ú/ > bùr-ú 'hook-pl'
$(\mathrm{C}[\mathrm{lab}]=\mathrm{C} 1)$
b. /tàb+-ó/ > tòb-ó
'fish(sp.)-pl'
$(\mathrm{C}[\mathrm{lab}]=\mathrm{C} 2)$
c. /círm-+-ú/ > cúrm-ú
'tree (sp.)'
$(\mathrm{C}[\mathrm{lab}]=\mathrm{C} 3)$
d. /páb+-ó/ > pób-ó
'cobra-pl'
$(\mathrm{C}[\mathrm{lab}]=\mathrm{C} 1$ and $\mathrm{C} 2)$
e. /mólm- ò/ > mólm-ò
'Muslim erudite'
$(\mathrm{C}[\mathrm{lab}]=\mathrm{C} 1$ and $\mathrm{C} 3)$

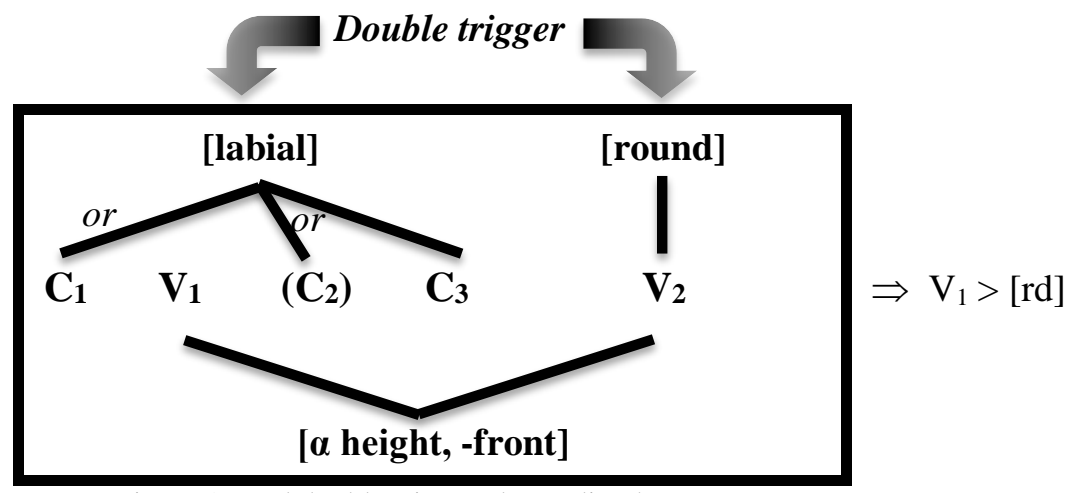

Figure 1. Laal doubly triggered rounding harmony

As shown in (4)-(8) below, all conditions must be met in order for rounding of $\mathrm{V}_{1}$ to take place.

(4) V1[rd], *V2[rd], Lab, Height, -Front, > no rounding, i.e. harmony is anticipatory
a. /gúmlíl//
$>$ gúmlíl
(*gúmlúl) 'zero'
b. /gōbə̄r/
$>$ gōbōr
(*gōbōr) 'cloud'

(5) *V2[rd], Lab, Height, -Front, > no rounding
a. /mò̀̀m-ว̀r/
$>$ mə̀̀̀m-ว̀r
'my grand-mother'
b. /pírmín/
> pírmín 'dust'

(6) V2[rd], *Lab, Height, -Front, > no rounding:
a. /gín+-ù/
$>$ gín-ù
'hunting.net-pl'
b. /sàg+-ó/
$>$ sàg-ó
'bag-pl'

\footnotetext{
${ }^{2}$ Although see 3.3 below for an exception.

${ }^{3}$ The underlying forms are given after application of all other phonological processes, e.g. $V_{2}$ deletion, other vowel harmonies etc.
} 
(7) V2[rd], Lab, *Height, -Front > no rounding ${ }^{4}$
a. /mà̀̀g+-ú/
$>$ mà̀̀g-ú
'tamarind-pl'
b. /6ว̀r+-ú/
$>$ bə̀r-ú
'plant.sp-pl'

(8) V2[rd], Lab, Height, *-Front > no rounding (no e-o example in the corpus):
a. /píírù/
$>$ pírù
ideophone
b. /bìrú /
$>$ bìrú
'burn'

\section{Subphonemic similarity threshold effects}

What is at work in this doubly triggered rounding harmony is a subphonemic similarity threshold effect. Being a case of assimilation, the similarity between both vowels plays a central role. This similarity is subphonemic (or subfeatural) in the sense that what is being evaluated here is the similarity between a phonologically round vowel $\left(\mathrm{V}_{2}\right)$ and a non-round vowel $\left(\mathrm{V}_{1}\right)$, which is however somewhat subfeaturally rounded by its environment (both triggers) through coarticulation. Finally this similarity needs to be quantitatively and qualitatively sufficient for rounding to take place: V1 needs to be rounded enough (hence the need for two triggers), and similar enough to $\mathrm{V}_{2}$ in the quality of rounding that characterizes it, as I will show in this section.

3.1 First threshold: degree of rounding coarticulation To break the first, quantitative threshold, the cumulative rounding effect of two triggers are needed: the round $V_{2}$ and the labial consonant both contribute some rounding to $\mathrm{V}_{1}$, and may trigger rounding of $\mathrm{V} 1$ only by joining forces.

The coarticulatory effect of a neighboring labial consonant on / $\mathbf{i}$ / (in the absence of any other labial or round segment in the word) is shown in the vowel plot in figure 2 below (with recordings from one male speaker, and formant measurements taken at the center of the vowel, as far as possible from formant transitions). As can be seen, the F2 of the entire vowel is significantly lowered by an adjacent labial consonant.

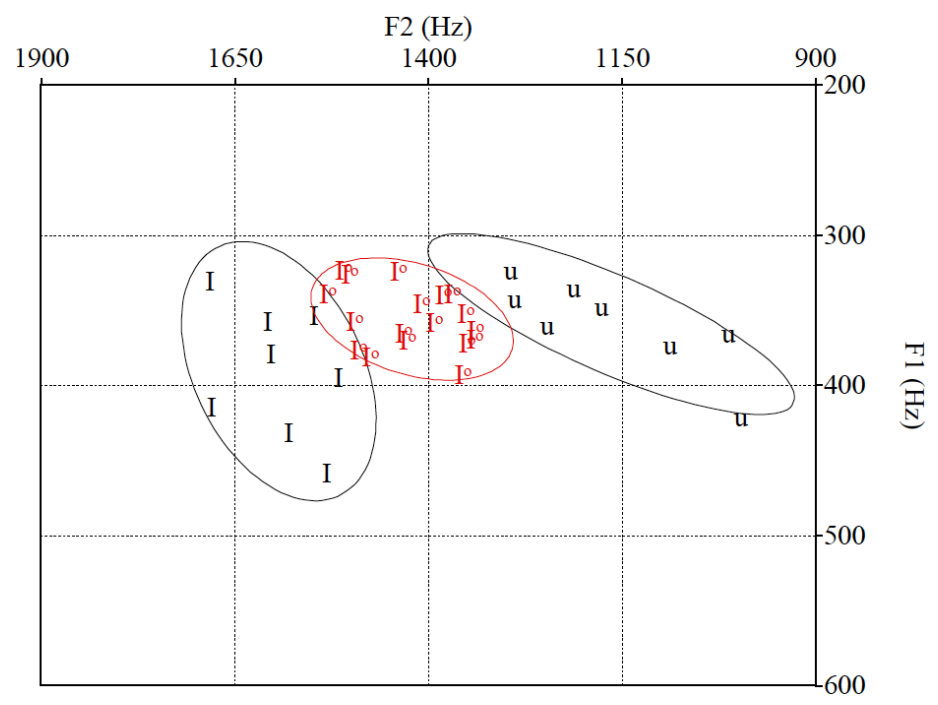

Figure 2. Coarticulatory rounding effect of labial consonants on adjacent $/ \dot{i} /\left(I=\dot{i}, I^{\circ}=\dot{i}+\right.$ labial $\left.C\right)$

The non-adjacency of the labial consonant and the target vowel in words of the form $\mathrm{CVC}_{2} \mathrm{C}_{3[\mathrm{lab}]} \mathrm{V}_{\text {[rd] }}$ such as (3)c cúrmú and (3)e mólmò should not be seen as a problem. The only $\mathrm{C}_{2}$ and $\mathrm{C}_{3}$ attested in such

${ }^{4}$ No CiCo example, due to High harmony: *hi-mid > hi-hi $(* \mathrm{CiCo}>\mathrm{CiCu})$ 


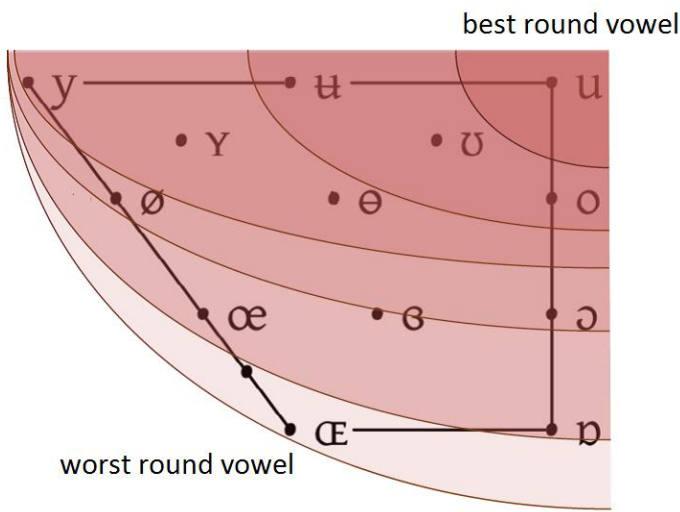

Figure 3. Rounding continuum (sketch)

words are indeed the two sonorants $\{1, \mathrm{r}\}$ and the labial $/ \mathrm{m} /$ respectively: $/ \mathrm{CVrmV}_{[\mathrm{rd}]} /$ and $/ \mathrm{CVlmV}_{[\mathrm{rd}]} / . \mathrm{The}$ sonorants $\{1, \mathrm{r}\}$ are expected to be relatively transparent to formant transitions between the previous vowel and the following labial consonant. As a consequence, in $/ \mathrm{Vrm} /$ and $/ \mathrm{Vlm} /$, the vowel formants are likely to be carried over onto the initial part of the sonorant, and the labial articulation of $/ \mathrm{m} /$ is likely to be anticipated during the articulation of the intervening sonorant, if not even before, allowing coarticulation between $/ \mathrm{m} /$ and $\mathrm{V}_{1}$ to occur through $/ \mathrm{l}, \mathrm{r} /$.

3.2 Second threshold: rounding enhancement and the rounding similarity scale The second, qualitative threshold has to do with the enhancement relationship that exists between vowel height, backness and rounding: Research by Terbeek (1977), Linker (1982) and Kaun (1995, 2004) has shown that the higher and the more back a round vowel is, the more round it is, articulatorily and perceptually. As a consequence, two round vowels of equal height/backness are more similar to each other than to other round vowels: $[\mathrm{u}]$ is more similar to $[\mathrm{y}]$ than to $[\varnothing]$ etc. as illustrated in the rounding continuum represented in Figure 3.

I claim that this must also be true of coarticulatorily rounded vowels, i.e. [ $\left.\dot{i}^{\circ}\right]$ is more similar to [u] than to [o] etc. Table 1 below presents a schematic rounding similarity scale for Laal, illustrating the similarity of subphonemically rounded vowels to [u] (chosen arbitrarily for illustration) at the phonemic and subphonemic levels. The similarity threshold beyond which a subphonemically rounded vowel has to agree with the following round vowel for the feature [round] in Laal is level 4, indicated by the shaded cell and the thick dotted line: both vowels need to be sufficiently subphonemically rounded (under the effect of both triggers, represented by the abbreviation "rd" without brackets) and identical for height and backness.

\begin{tabular}{|l|l|l|l|}
\hline & $\begin{array}{l}\text { Degree of } \\
\text { similarity }\end{array}$ & Property & Set of vowels that are similar to [u] \\
\hline Phonemic level & 5 & {$[\mathrm{rd}]$} & $\mathrm{u}$ \\
\hline \multirow{5}{*}{ Subphonemic level } & 4 & $\mathrm{rd} /[$-front]/height & $\mathrm{i}^{\circ}$ \\
\cline { 2 - 4 } & 3 & $\mathrm{rd} /$ height & $\mathrm{i}^{\mathrm{o}}, \mathrm{i}^{\circ}$ \\
\cline { 2 - 4 } & 2 & $\mathrm{rd} /[$-front] & $\dot{\mathrm{i}}^{\mathrm{o}}, \partial^{\circ}, \mathrm{a}^{\mathrm{o}}$ \\
\cline { 2 - 4 } & 1 & $\mathrm{rd}$ & $\mathrm{V}^{\circ}$ \\
\hline
\end{tabular}

Table 1. Rounding similarity scale in Laal

The phonemic level 5 thus acts as an attractor or magnet (Mohanan 1993, Wayment 2009): Once $\mathrm{V}_{1}$ reaches level $4\left(\left[\dot{i}^{\circ}\right]\right.$ in Table 1$)$, it has gone too far into the magnetic field of level $5[\mathrm{u}]$ to resist its attraction. This is schematically represented in Tables 2 and 3 below. 


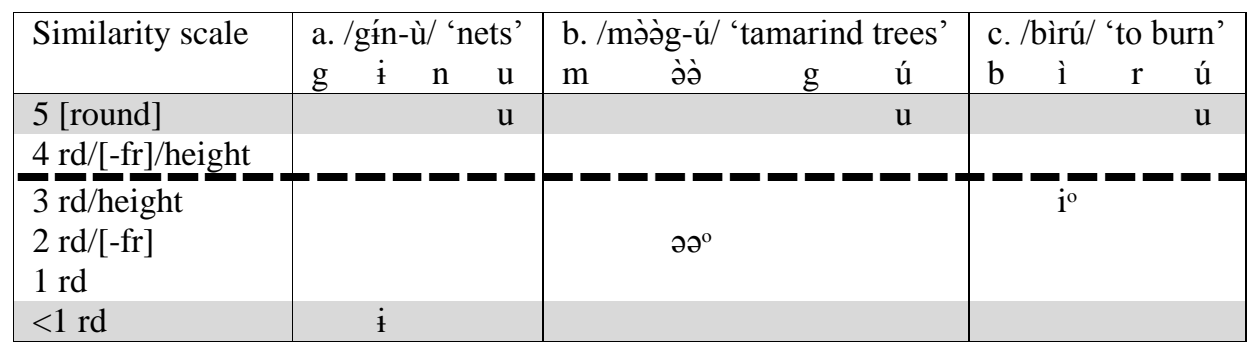

Table 2: Below the threshold: no rounding

a. *Lab, Height, -Front; b. Lab, *Height, -Front; c. Lab, Height, *-Front

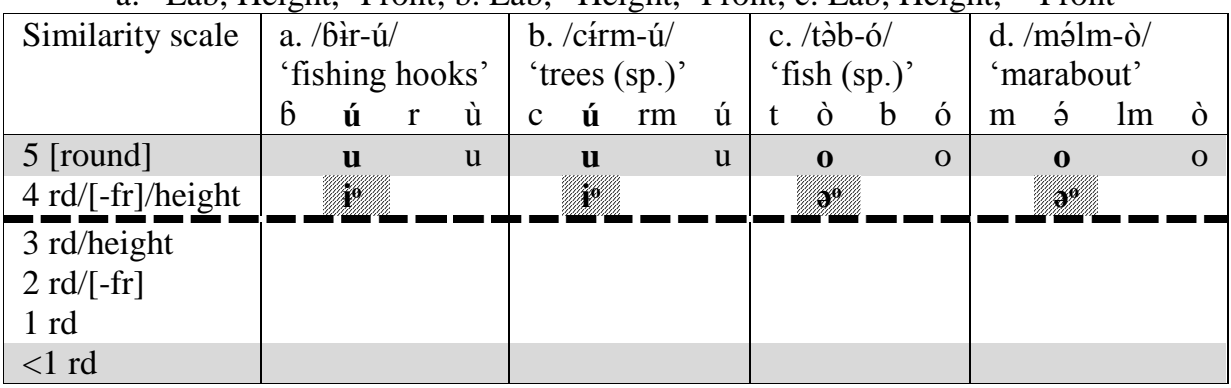

Table 3: Threshold effect: Lab, Height, -Front > rounding

3.3 A complication: opacity of intervening $/(C) w / \quad$ I now turn to one more intriguing property of the doubly triggered rounding harmony in Laal, namely the opacity of intervening /w/. Stem-initial /w/ is on a par with all other labial consonants in co-triggering the rounding harmony, as shown by the only attested case in (9).

(9) /wòór+-ó/ > wòòr-ó 'mongoose-pl' (

Intervening $/ \mathrm{w} /$, on the other hand, not only does not trigger the expected rounding harmony in (10)a-f, it blocks it in (10)g despite the presence of a labial $C_{1}$ which should co-trigger harmony. Note that $/ \mathrm{w} /$ blocks the harmony even when separated from the target vowel by an intervening stop, as shown with the only attested case in (10)h.

(10) Opacity of intervening /w/ (exhaustive list):
a. /sáw+-ò/ > sáw-ò
'warthogs'
$\left({ }^{*} s \boldsymbol{o} w o ̀\right)$
$\left(\mathrm{w}=\mathrm{C}_{2}\right)$
b. $\mathrm{b} / \mathrm{s} \partial \overline{\mathrm{w}}+-\overline{\mathrm{o}} />\mathrm{s} \overline{\mathrm{w}} \mathrm{w}-\overline{\mathrm{O}}$
'fish(sp.)-pl'
$\left({ }^{*} s \overline{\boldsymbol{\sigma}} w \bar{o}\right)$
$\left(\mathrm{w}=\mathrm{C}_{2}\right)$
c. /gáw+-ò/ > gáw-ò
'hunters'
(*gówò)
$\left(\mathrm{w}=\mathrm{C}_{2}\right)$
d. /gáw+-ó/ > gáw-ó
'elephant traps'
(*gówó)
$\left(\mathrm{w}=\mathrm{C}_{2}\right)$
e. $/ \mathrm{j} \bar{\partial} \mathrm{W}+-\overline{\mathrm{O}} />\mathrm{j} \overline{\mathrm{W}} \mathrm{W}-\overline{\mathrm{o}}$
'cheetahs'
$\left({ }^{*} \overline{\boldsymbol{o}} w \bar{o}\right)$
$\left(\mathrm{w}=\mathrm{C}_{2}\right)$
f. /táw+-ó/ > tów-ó
'shields'
(*tówó)
$\left(\mathrm{w}=\mathrm{C}_{2}\right)$
g. /máw+-ó/ > máw-ó
'scorpions'
(*mówó)
$\left(\mathrm{w}=\mathrm{C}_{2}\right)$
h. /jágw+-ó/
> jágw-ó 'hats'
$(* j \boldsymbol{o} g$ wó $) \quad\left(\mathrm{w}=\mathrm{C}_{3}\right)$

This pattern is also a general morpheme structure condition: no case of a round vowel followed by $/(\mathrm{C}) \mathrm{w} /$ is attested among the 2200 stems listed in the lexicon.

This intriguing dual behavior of $/ \mathrm{w} /$ is not well understood yet. One could hypothesize that there is a difference in $\mathrm{C}-\mathrm{V}$ perceptual contrast between $[\mathrm{wU}]$ and $[\mathrm{Uw}]$ (where $\mathrm{U}$ represents a rounded vowel), due to a possible articulatory/acoustic asymmetry between the initial rounding and the final unrounding involved in the articulation of [w]: [wU] may be easily perceived as a CV sequence, whereas the [w] in $[\mathrm{Uw}]$ may be too easily confusable with $[\mathrm{U}](\mathrm{Uw} \sim \mathrm{U})$, making the consonant /w/ difficult to recover. Such a hypothesis seems at first sight to be compatible with the fact that external cues are usually more salient at CV transitions than at VC transitions ("boost at onset", cf. Wright 2004:43, and references therein). 


\section{Subphonemic phonology}

There is evidence that this subphonemically driven process is phonological rather than simply phonetic. First, according to impressionistic data only, the alternation does not seem to be sensitive to speech rate. Second, the opacity of intervening $/ \mathrm{w} /$ seen above clearly indicates that phonetics alone cannot explain the alternation: $/ \mathrm{w} /$ provides at least as much coarticulatory rounding to the neighboring vowel as a any other labial consonants, and yet blocks rounding. Finally, the doubly triggered rounding harmony is only attested in stratum 1 phonology: in stratum 2 , rounding harmony is unconditional and systematic, as illustrated in (11) below with transitive verbs with object suffixes.

(11) Verb + -ò(n) - -ù(n) 'her' and -nǔ 'us (ex.)' object suffixes (stratum 2):
a. /tírt-ùn/
$>$ túr-ùn
'put her across'
*Lab
b. /dàg+-òn/
$>$ dòg-òn
'drag her'
*Lab
c. /dàg+-nǔ/
$>$ dòg-nŭ 'drag us (ex.)'
*Lab, *Height
d. /léér+-nǔ/
$>$ lüóór-nŭ 'wrap us'
e. /ków-òn/
$>$ ków-òn
'be insufficient for us'
*Lab, *Height, *-Front
Intervening /w/

Given the requirement that words be maximally disyllabic in Laal, the domain of application of stratum 1 and stratum 2 processes is exactly the same. It is thus very unlikely for the coarticulatory effects of a round V2 or a neighboring labial consonant on V1 to change with the stratum to which the suffix belongs.

The Laal doubly triggered rounding harmony thus shows that phonology includes a subfeatural level, i.e. distinctions that cannot be captured by phonological features, but are active in the phonology, in particular in assimilatory processes. In the next section, I propose an analysis of this alternation using Agreement by Correspondence theory, showing how this theory can account for such processes.

\section{Subphonemic Agreement by Correspondence}

Agreement by Correspondence (ABC) is a theory of assimilation couched in Optimality Theory (Prince and Smolensky 1993) that was initially developed for long-distance consonant agreement (Walker 2000a,b, 2001; Hansson 2001; Rose \& Walker 2004). It was recently extended to vowel harmony (Sasa 2009; Walker 2009; Rhodes 2012), as well long-distance consonant dissimilation (Bennett 2013). The theory I propose in this section relates to a recent and ongoing effort to account for local effects of assimilation and dissimilation in ABC (Inkelas and Shih 2013a,b; Shih 2013; Sylak-Glassman 2013).

The central insight of $\mathrm{ABC}$ is that (dis)harmony is driven by a similarity threshold effect. Similarity is built into the system, rather than stipulated: harmony between segments is viewed, not as spreading, but as agreement between segments in a correspondence relationship based on phonetic/phonological similarity. This surface correspondence is unstable (Inkelas and Shih 2013): two (or more) segments are sufficiently similar to interact (they are in correspondence), but are too uncomfortably similar to co-exist within a certain distance. Two repairs are possible: harmony (more similarity) and disharmony (less similarity).

This theory sounds particularly well suited to account for phonological teamwork processes, which we have seen are driven by subphonemic similarity threshold effects. $\mathrm{ABC}$ can already handle the similarity threshold effects it was built to handle: I propose to extend its application to subphonemic effects, by enabling its representations access to subphonemic information.

5.1 Formal apparatus (re)defined The basic mechanics of $\mathrm{ABC}$ involve two types of surfaceoriented constraints: CORR-XX constraints establish surface correspondence between segments X similar in a particular feature or set of features (e.g. obstruents, coronals, liquids etc.), while IDENT-XX[F] constraints enforce agreement in the feature $[\mathrm{F}]$ between segments in a correspondence set. Both types of constraints are ranked higher than the constraints enforcing faithfulness to the assimilating feature (usually IDENT$\mathrm{IO} / \mathrm{OI}[\mathrm{F}])$.

Phonological similarity, as we have seen, can be gradient (e.g. different degrees of rounding) rather than categorical ([+round] vs. [-round]). Defining the CORR constraints as the formal representation of 
similarity relations in $\mathrm{ABC}$ theory comes with two important consequences.

First, there is no reason to prevent CORR constraints from referencing gradient subphonemic information. Each degree, phonemic or subphonemic, in any given scale corresponding to a phonetic property (e.g. rounding or height) thus corresponds to a separate CORR-XX $(\mathrm{P} \geq n)$ constraint, defined as in (12) below.

(12) CORR-XX $(\mathrm{P} \geq \mathrm{n})$ : Any segments within an output string of segments are in correspondence if their similarity in the phonetic property $\mathrm{P}$ is at least $\mathrm{n}$ on the scale corresponding to $\mathrm{P}$.

$\rightarrow$ Assign one violation per pair of neighboring segments that meet the criteria but fail to correspond5

All the constraints referring to the degrees of a given scale are ranked according to the degree they represent (à la de Lacy 2002), as schematically illustrated in (13) below.

\section{(13) CORR-XX $(\mathrm{P} \geq n+2)\rangle /$ CORR-XX $(\mathrm{P} \geq n+1)\rangle)$ CORR-XX $(\mathrm{P} \geq n)$}

The second consequence of defining CORR as the representation of similarity is that one has to acknowledge the existence of as many correspondence sets in a given string as there are similarity relations among the segments it is formed of. The definition of correspondence that I adopt here is thus one that allows multiple correspondence relations, rather than only one, contra McCarthy's (2010), and Bennett (2013:184).

As a consequence, the scope of the surface IDENT-XX[F] constraints is not restricted enough: a general IDENT-XX[F] constraint enforces agreement between corresponding segments, i.e. members of a any correspondence set. If several such sets exist in a string, the theory needs to enforce agreement only among the relevant set. In the case of subphonemic agreement, if the threshold for agreement is, say $P \geq n+2$, the theory must ensure that IDENT-XX[F] applies only to the correspondence set defined by CORR-XX $(\mathrm{p} \geq n+2)$, and not to the one defined by $\operatorname{CORR}-\mathrm{XX}(\mathrm{P} \geq n+1)$ or $\operatorname{CORR}-\mathrm{XX}(\mathrm{P} \geq n)$. In conclusion, IDENT-XX[F] constraints need to be made dependent on a specific CORR-XX(P- $n)$ constraint. I propose to formally represent this dependence by coindexing both constraints, as in (14) below.

Additionally, since the feature $[\mathrm{F}]$ on which $\operatorname{IDENT}_{a^{-}} \mathrm{XX}[\mathrm{F}]$ is stated must by definition be a feature that increases an already existing similarity between agreeing segments, $[\mathrm{F}]$ may only be the phonological feature that corresponds to the phonetic property $\mathrm{P}$ on which $\mathrm{CORR}_{\alpha}-\mathrm{XX}(\mathrm{P}-n)$ is stated, i.e. [F] (e.g. [round]) must represent the phonemic level on the phonetic similarity scale defined for P (e.g. rounding): $[\mathrm{F}] \subset \mathrm{P}$.

(14) IDENT $\alpha_{0}-\mathrm{XX}[\mathrm{F}]$ : Any segments in an output string agree in the phonological feature $[\mathrm{F}]$ iff they are in the correspondence relation defined as $\mathrm{CORR}_{\alpha}-\mathrm{XX}(\mathrm{P} \geq n)$, and $[\mathrm{F}] \subset \mathrm{P}$.

$\rightarrow$ Assign one violation per pair of neighboring segments that partake in the relevant correspondence relation but fail to agree in $[\mathrm{F}]$.

5.2 Analysis of the Laal data The two constraints establishing and enforcing the relevant correspondence and agreement in Laal are $\mathrm{CORR}_{\alpha^{-}} \mathrm{VV}(\mathrm{RD} \geq 4)$ and $\operatorname{IDENT}_{\alpha^{-}} \mathrm{VV}(\mathrm{RD})$, defined in (15) and (16) respectively.

(15) $\mathrm{CORR}_{\alpha}-\mathrm{VV}(\mathrm{RD} \geq 4)$ : Any two vowels within an output string of segments are in correspondence if their similarity in (phonemic or subphonemic) rounding is at least 4 (defined as $\mathrm{rd} /[$-front]/height) on the Rounding Similarity Scale.

(16) IDENT $\alpha^{-} \mathrm{VV}[\mathrm{RD}]$ : Any two vowels in a given output string agree in the phonological feature [round] iff they are in the correspondence relation defined as $\mathrm{CORR}_{\alpha}-\mathrm{VV}[\mathrm{RD} \geq 4]$.

The CORR-XX $(\mathrm{RD} \geq n)$ constraints at work in Laal are ranked according to the following hierarchy:

\footnotetext{
${ }^{5}$ Following Hansson (2007: 402-404), I choose to assess correspondence and agreement on local pairs of segments to avoid the pathological predictions found with global evaluation.
} 


\begin{tabular}{|c|c|}
\hline Similarity scale & Correspondence hierarchy \\
\hline Degree 4: rd/[-front]/height & CORR-VV(RD $\geq 4)$ \\
\hline Degree 3: rd/height & CORR-VV $(\mathrm{RD} \geq 3)$ \\
\hline Degree $2:$ rd/[-front] & CORR-VV $(\mathrm{RD} \geq 2)$ \\
\hline Degree 1: rd & CORR-VV $(\mathrm{RD} \geq 1)$ \\
\hline
\end{tabular}

Table 4. Correspondence hierarchy

Constraints enforcing faithfulness between input and output also play an important role. Two such constraints are needed: IDENT-OI[RD], enforcing faithfulness to the feature [round] (i.e. penalizing rounding), and IDENT-IO[RD], enforcing faithfulness to the absence of [round] (i.e. penalizing unrounding), defined in (17) and (18) below.

(17) IDENT-OI[RD]: For every [round] feature in the output, a corresponding [round] feature must exist in the input. (Assign one violation for each segment gaining the feature [round].)

(18) IDENT-IO[RD]: For every [round] feature in the input, a corresponding [round] feature must exist in the output. (Assign one violation for each segment losing the feature [round].)

At this point, only the three IDENT constraints need to be ranked. IDENT $\alpha^{-} \mathrm{VV}[\mathrm{RD}]$, enforcing rounding needs to be ranked higher than IDENT-OI[RD], which prevents rounding. Additionally, since unrounding is strictly unattested in Laal, IDENT-OI[RD] is undominated, which yields the preliminary constraint ranking in (19).

(19) Hasse diagram:

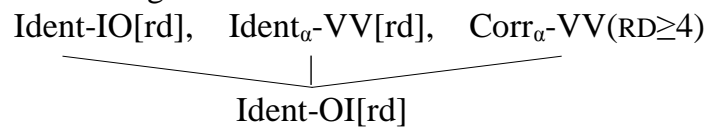

The tableau in (20) below illustrates how those ranked constraints enforce rounding harmony for the input /6ir-u/. Candidates $a, b$ and $c$ lose because the two vowels should be in correspondence, thus violating $\mathrm{CORR}_{\alpha^{-}} \mathrm{VV}(\mathrm{RD} \geq 4)$. Candidate $c$ additionally violates the undominated constraint against unrounding IDENT-IO[RD]. Finally candidate $d$ violates IDENT $\alpha_{\alpha}-\mathrm{VV}[\mathrm{RD}]$, since the two vowels in correspondence fail to agree, which leaves $e$ as the optimal candidate, due to the crucial IDENT $_{\alpha}-\mathrm{VV}$ [RD] > IDENT-OI[RD] ranking favoring agreement over faithfulness to the input.

(20) /bìr-ú/ $\rightarrow$ [bùrú] 'fish hooks'

\begin{tabular}{|c|c|c|c|c|c|}
\hline & /Gìr-ú/ & IDENT-IO[RD] & $\mathrm{CORR}_{\alpha}-\mathrm{VV}(\mathrm{RD} \geq 4)$ & $\mathrm{IDENT}_{\alpha}-\mathrm{VV}[\mathrm{RD}]$ & IDENT-OI[RD] \\
\hline a. & $6 \grave{i ̀}^{\circ} r-u ́$ & & $* !$ & & \\
\hline b. & Gùr-ú & & $* !$ & & $*$ \\
\hline d. & $6 \grave{i ̀}_{\alpha}{ }_{\alpha} r-u_{\alpha}$ & & & $* !$ & \\
\hline e. $\sigma$ & bù̀ ${ }_{\alpha} r-u_{\alpha}$ & & & & $*$ \\
\hline f. & $6 \grave{i ̀}^{\circ} r-\dot{t}$ & *! & & & \\
\hline
\end{tabular}

Whenever the two vowels are not in correspondence, i.e. do not reach level 4 on the Rounding Similarity Scale, rounding of $\mathrm{V}_{1}$ does not occur, because the violation of the constraint enforcing agreement $\left(\mathrm{IDENT}_{\alpha}-\mathrm{VV}[\mathrm{RD}]\right)$ is dependent upon whether the two vowels are in correspondence (by being coindexed with $\mathrm{CORR}_{\alpha}-\mathrm{VV}(\mathrm{RD} \geq 4)$ ). Consequently for all the forms listed in examples (4)-(8), the optimal candidate is entirely faithful to its input, as illustrated for /mèn-ù/ in the tableau in (21). 
(21) /mèn-ù/ $\rightarrow$ [mèn-ù] 'hoes'

\begin{tabular}{|c|c|c|c|c|c|}
\hline & /mèn-ù/ & IDENT-IO[RD] & $\mathrm{CORR}_{\alpha}-\mathrm{VV}(\mathrm{RD} \geq 4)$ & IDENT $_{\alpha}-\mathrm{VV}[\mathrm{RD}]$ & IDENT-OI[RD] \\
\hline a. $\sigma$ & mè̀ & & & & \\
\hline b. & müòn-ù & & & & $* !$ \\
\hline c. & mè̀n-ì & $* !$ & & & \\
\hline
\end{tabular}

To account for the directionality of the harmony, I propose an undominated positional faithfulness constraint penalizing any change in rounding (gain or loss of the feature [round]) in the second (and most often last) syllable of a word, defined in (22), and illustrated in tableau (23).

(22) IDENT- $\sigma_{2}-[\mathrm{RD}]$ : for every [round] feature in the second syllable of an output form, a corresponding [round] feature must exist in its input form, and for every [round] feature in the second syllable of an input form, a corresponding [round] feature must exist in its output form. (Assign one violation for each segment gaining the feature [round].)

(23) /gōbār/ $\rightarrow$ /[gōbə̄r] 'could'

\begin{tabular}{|c|c|c|c|c|c|c|}
\hline & /gōbə̄r/ & $\begin{array}{l}\text { IDENT- } \\
\text { IO[RD] }\end{array}$ & $\begin{array}{l}\text { IDENT- } \\
\sigma_{2}[\mathrm{RD}] \\
\end{array}$ & $\mathrm{CORR}_{\alpha}-\mathrm{VV}(\mathrm{RD} \geq 4)$ & $\mathrm{IDENT}_{\alpha}-\mathrm{VV}[\mathrm{RD}]$ & $\begin{array}{l}\text { IDENT- } \\
\text { OI[RD] }\end{array}$ \\
\hline a. & gōbə̄ōr & & & $* !$ & & \\
\hline b. & gōbōr & & $* !$ & $* !$ & & $*$ \\
\hline c. $\sigma$ & $\mathrm{go}_{\alpha} \mathrm{b} \bar{\partial}_{\alpha}{ }_{\alpha} \mathrm{r}$ & & & & $*$ & \\
\hline d. & $g \overline{\mathrm{o}}_{\alpha} \mathrm{b} \overline{\mathrm{o}}_{\alpha} \mathrm{r}$ & & $* !$ & & & $*$ \\
\hline e. & $\mathrm{g} \bar{\partial}^{\circ} \mathrm{b} \bar{\partial}^{\circ} \mathrm{r}$ & $* !$ & & & & \\
\hline
\end{tabular}

Finally, to account for the opacity of intervening $/(\mathrm{C}) \mathrm{w} /$, I temporarily resort to an unsatisfying markedness constraint $* \mathrm{U}(\mathrm{C}) \mathrm{W}$, defined in (24), which needs to be undominated.

(24) $* \mathrm{U}(\mathrm{C}) \mathrm{w}$ : Assign a violation for each round vowel followed (with or without an intervening consonant) by /w/

(25) /mów-ó/ $\rightarrow$ méwó 'scorpions'

\begin{tabular}{|c|c|c|c|c|c|c|c|}
\hline & /məw-o/ & $* \mathrm{U}(\mathrm{C}) \mathrm{W}$ & $\begin{array}{l}\text { IDENT- } \\
\sigma_{2}[\mathrm{RD}] \\
\end{array}$ & $\begin{array}{l}\text { IDENT- } \\
\text { IO[RD] }\end{array}$ & $\begin{array}{l}\mathrm{CORR}_{\alpha} \text {-VV } \\
(\mathrm{RD} \geq 4)\end{array}$ & $\mathrm{IDENT}_{\alpha}-\mathrm{VV}[\mathrm{RD}]$ & $\begin{array}{l}\text { IDENT- } \\
\text { OI[RD] } \\
\end{array}$ \\
\hline a. & máo w-ó & & & & $* !$ & & \\
\hline b. & mów-ó & $* !$ & & & $*$ & & * \\
\hline c. & máo w-ว́o & & & $* !$ & $*$ & & \\
\hline j. $\sigma$ & mə́o ${ }_{\alpha} \mathrm{W}-\mathrm{o}_{\alpha}$ & & & & & $*$ & \\
\hline k. & mó ${ }_{\alpha} \mathrm{W}$-ó ${ }_{\alpha}$ & $* !$ & & & & & * \\
\hline
\end{tabular}

Note that $\mathrm{CORR}_{\alpha}-\mathrm{VV}(\mathrm{RD} \geq 4)$ now has to be ranked higher than $\operatorname{IDENT}_{\alpha}-\mathrm{VV}[\mathrm{RD}]$, in order to enforce correspondence (compare candidates $a$ and $j$ in the tableau in (26) below).

$(26) * \mathrm{U}(\mathrm{C}) \mathrm{w}, \quad$ Ident- $\sigma 2[\mathrm{rd}], \quad$ Ident-IO[rd], Corr $\alpha-\mathrm{VV}(\mathrm{RD} \geq 4)$

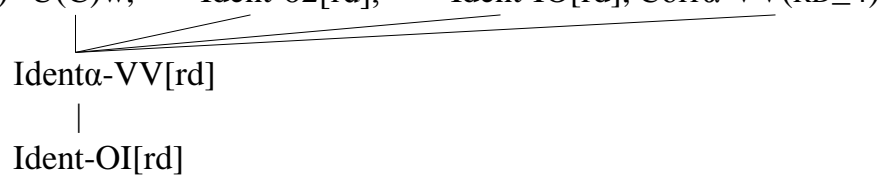

It is interesting to note that intervening /w/ blocks harmony, but does not trigger dissimilation. This is a case where the system "chooses" to keep the unstable correspondence, the "uncomfortable" level of similarity unchanged. 


\section{Conclusion}

The doubly triggered rounding harmony attested in Laal involves a subphonemic/subfeatural similarity threshold effect, which is the result of the phonologization of a perceptual similarity/confusability effect, stemming from coarticulation. Assimilation "fixes" an unstable/uncomfortable level of similarity (making perceptual contrast difficult). I argued that this alternation shows that phonology has a gradient subphonemic/subfeatural component, which is different from mere phonetic information: different degrees of subfeatural coarticulatory rounding are represented and active in phonology.

I have also argued that these effects can be built in Agreement by Correspondence theory, particularly well-suited to deal with processes involving similarity threshold effects. This is a promising step showing that both local and long-distance effects of assimilation may be insightfully captured by one and the same model.

\section{References}

Bennett, William G. 2013. Dissimilation, Consonant Harmony, and Surface Correspondence. Ph.D. dissertation, NJCU Rutgers.

Campbell, Lyle. 1974. Phonological features: Problems and proposals. Language 50(1): 52-65.

de Lacy, Paul V. 2002. The Formal Expression of Markedness. Doctoral dissertation, University of Massachusetts, Amherst. Amherst, MA: GLSA Publications. ROA 542.

Flemming, Edward S. 1997. Phonetic Detail in Phonology: Towards a unified account of assimilation and coarticulation. In Suzuki, K. and D. Elzinga (eds.), Southwest Workshop on Optimality Theory: Features in OT (SWOT), Coyote Papers.

Hansson, Gunnar Ólafur. 2001. Theoretical and Typological Issues in Consonant Harmony. Ph.D. dissertation. University of California, Berkeley.

Hansson, Gunnar Ólafur. 2007. Blocking Effects in Agreement by Correspondence. Linguistic Inquiry, 38(2): $395-409$.

Hayes, Bruce and Donca Steriade. 2004. Introduction: the phonetic bases of phonological Markedness. In Hayes, Bruce et al. (eds.), Phonetically Based Phonology. Cambridge: CUP. 1-33.

Hayes, Bruce, Robert Kirchner and Donca Steriade. 2004. Phonetically Based Phonology. Cambridge: CUP

Inkelas, Sharon and Stephanie Shih. 2013. A subsegmental correspondence approach to contour tone (dis)harmony. Paper presented at Phonology 2013, University of Massachusetts, Amherst, November 8-10, 2013.

Inkelas, Sharon and Stephanie Shih. Unstable surface correspondence as the source of local conspiracies. Paper presented at NELS 44, University of Connecticut, Oct. 18-20, 2013.

Kaun, Abigail. 1995. The typology of rounding harmony: an optimality-theoretic approach. Unpublished doctoral dissertation. UCLA.

Kaun, Abigail. 2004. The typology of rounding harmony. In B. Hayes et al. (eds.), Phonetically Based Phonology. 2004. Cambridge: CUP.

Kuhl, P. K. 1991. Human adults and human infants show a 'perceptual magnet effect' for the prototypes of speech categories, monkeys do not. Perception \& Psychophysics, 50, 93-107.

Lionnet, Florian. In prep. Phonological Teamwork: Cumulative Effects in Phonology. Ph.D. Dissertation. University of California, Berkeley.

Linker, Wendy. 1982. Articulatory and acoustic correlates of labial activity in vowels: A cross-linguistic study. Doctoral dissertation, UCLA. Published in UCLA Working Papers in Phonetics 56.

McCarthy, John. 2010. Agreement by correspondence without Corr constraints. Ms. University of Massachussetts, Amherst.

Mohanan, K.P. 1993. Fields of attraction in phonology. In Goldsmith, John (ed.), The Last Phonological Rule. Chicago: University of Chicago Press.

Ohala, John. 1993. The phonetics of sound change. In Charles Jones (ed.), Historical Linguistics: Problems and Perspectives. London: Longman. pp. 237-278.

Rhodes, Russell. 2012. Vowel Harmony as Agreement by Correspondence. Annual Report of the UC Berkeley Phonology Lab (2012), pp.138-168.

Rose, Sharon and Rachel Walker. 2004. A typology of consonant agreement as correspondence. Language 80:475-31.

Sasa, Tomomasa. 2009. Treatment of Vowel Harmony in Optimality Theory. Ph.D. dissertation, University of Iowa.

Shih, Stephanie. 2013. Consonant-tone interaction as Agreement by Correspondence. Ms. Stanford University.

Sohn, Ho-Min. 1975. Woleaian Reference Grammar. Honolulu: University of Hawaii Press.

Steriade, Donca. 1999. Phonetics in phonology: the case of laryngeal neutralization. In Matthew Gordon (ed.), Papers in Phonology 3. (UCLA Working Papers in Linguistics 2) Los Angeles: Department of Linguistics, CULA, 25146. http://www.linguistics.ucla.edu/people/steriade/papers/phoneticsInPhonology.pdf 
Stevens, Kenneth N. 1998. Acoustic phonetics. MIT Press.

Suzuki, Keiichiro. 1997. Double-sided Effects in OT: Sequential Grounding and Local Conjunction. In Suzuki, K. and D. Elzinga (eds.), Proceedings of the 1995 Southwest Workshop on Optimality Theory: Features in OT (SWOT), Coyote Papers.

Terbeek, Dale. 1977. A cross-language multidimensional scaling study of vowel perception. PhD dissertation, UCLA. Published in UCLA Working Papers in Phonetics 37.

Walker, Rachel. 2000a. Long-distance consonantal identity effects. Proceedings of the Nineteenth West Coast Conference on Formal Linguistics (WCCFL 19), edited by Roger Billerey and Brook Danielle Lillehaugen, Somerville, MA: Cascadilla, 532-545.

Walker, Rachel. 2000b. Yaka nasal harmony: Spreading or segmental correspondence? Proceedings of the $26^{\text {th }}$ Annual Meeting of the Berkeley Linguistics Society, edited by Lisa J. Conathan, Jeff Good, Darya Kavitskaya, Alyssa B. Wulf and Alan. C.L. Yu, Berkeley, CA: Berkeley Lingusitics Society, 321-332.

Walker, Rachel. 2001. Consonantal correspondence. Proceedings of the Workshop on the Lexicon in Phonetics and Phonology: Papers in Experimental and Theoretical Linguistics, vol. 6, edited by Robert Kirchner, Joe Pater and Wolf Wikeley, Edmonton: University of Alberta Department of Linguistics, vol. 6, 73-84

Walker, Rachel. 2009. Similarity-sensitive blocking and transparency in Menominee. Paper presented at the $83^{\text {rd }}$ Annual Meeting of the Linguistic Society of America. San Francisco, California. 9 January 2009. http://wwwbcf.usc.edu/ rwalker/MenomineeLSAHdt.pdf

Wayment, Adam. 2009. Assimilation as Attraction: Computing Distance, Similarity and Locality in Phonology. Ph.D. dissertation. Johns Hopkins University.

Wright, Richard. 2004. A review of perceptual cues and cue robustness. In Hayes, Bruce et al. (eds.), Phonetically Based Phonology. Cambridge: CUP. 34-57. 